\title{
Field-based evidence for consistent responses of bacterial communities to copper contamination in two contrasting agricultural soils
}

\author{
Jing $\mathrm{Li}^{1,2}$, Yi-Bing $\mathrm{Ma}^{3}{ }^{3}$ Hang-Wei Hu${ }^{4}$, Jun-Tao Wang ${ }^{1,2}$, Yu-Rong Liu ${ }^{1}$ and Ji-Zheng He ${ }^{1,4 *}$ \\ ${ }^{1}$ State Key Laboratory of Urban and Regional Ecology, Research Center for Eco-Environmental Sciences, Chinese Academy of Sciences, Beijing, China \\ ${ }^{2}$ College of Resources and Environment, University of Chinese Academy of Sciences, Beijing, China \\ ${ }^{3}$ National Soil Fertility and Fertilizer Effects Long-term Monitoring Network, Institute of Agricultural Resources and Regional Planning, Chinese Academy of \\ Agricultural Sciences, Beijing, China \\ ${ }^{4}$ Faculty of Veterinary and Agricultural Sciences, The University of Melbourne, Parkville, VIC, Australia
}

\section{Edited by:}

Chuanlun Zhang, University of

Georgia, USA

\section{Reviewed by:}

Christoph Mueller, University of Giessen, Germany

Anne E. Taylor, Oregon State

University, USA

*Correspondence:

Ji-Zheng He, State Key Laboratory of Urban and Regional Ecology,

Research Center for

Eco-Environmental Sciences,

Chinese Academy of Sciences, 18

Shuangqing Road, Beijing 100085,

China

e-mail: jzhe@rcees.ac.cn;

jizheng.he@unimelb.edu.au
Copper contamination on China's arable land could pose severe economic, ecological and healthy consequences in the coming decades. As the drivers in maintaining ecosystem functioning, the responses of soil microorganisms to long-term copper contamination in different soil ecosystems are still debated. This study investigated the impacts of copper gradients on soil bacterial communities in two agricultural fields with contrasting soil properties. Our results revealed consistent reduction in soil microbial biomass carbon (SMBC) with increasing copper levels in both soils, coupled by significant declines in bacterial abundance in most cases. Despite of contrasting bacterial community structures between the two soils, the bacterial diversity in the copper-contaminated soils showed considerably decreasing patterns when copper levels elevated. High-throughput sequencing revealed copper selection for major bacterial guilds, in particular, Actinobacteria showed tolerance, while Acidobacteria and Chloroflexi were highly sensitive to copper. The thresholds that bacterial communities changed sharply were 800 and 200 added copper $\mathrm{mg} \mathrm{kg}^{-1}$ in the fluvo-aquic soil and red soil, respectively, which were similar to the toxicity thresholds (EC50 values) characterized by SMBC. Structural equation model (SEM) analysis ascertained that the shifts of bacterial community composition and diversity were closely related with the changes of SMBC in both soils. Our results provide field-based evidence that copper contamination exhibits consistently negative impacts on soil bacterial communities, and the shifts of bacterial communities could have largely determined the variations of the microbial biomass.

Keywords: copper contamination, soil bacterial community, diversity, abundance, community composition, soil microbial biomass carbon, field experiment

\section{INTRODUCTION}

Soils represent the largest sink for copper released into the environment by anthropogenic activities, such as sewage irrigation, mining activities, municipal waste disposal, and intensive use of pesticides and herbicides (Smith, 2009; Zhuang et al., 2009). Approximately 3.4 million ton copper is released to the terrestrial surface every year (Zhou et al., 2000). High copper concentrations have been found in paddy soils $\left(109-1313 \mathrm{mg} \mathrm{kg}^{-1}\right.$ ) near mining sites (Zhuang et al., 2009), and vineyard soils increasing from background levels of $10 \mathrm{mg} \mathrm{kg}^{-1}$ to approximately $250 \mathrm{mg}$ $\mathrm{kg}^{-1}$ with intensive use of copper-based fungicides (Pietrzak and McPhail, 2004). Moreover, it was predicted that up to $20 \%$ of China's arable lands were contaminated by heavy metals and the areas will continuously expand due to the intensification of human activities in the coming decades, especially the agricultural soils (Li et al., 2014b).

Microorganisms are highly diverse and ubiquitous in soil ecosystems, and participate in a variety of key ecosystem functions such as nutrient cycling, feedback responses to climate change and biomass production. A stable microbial community contributes essentially to stabilizing soil structure and maintaining soil ecosystem services (Bissett et al., 2013). Moderate level of copper regarded as a micronutrient element is necessary for microorganisms to carry out the normal metabolic activities (Giller et al., 2009). However, excessive inputs of it into soil ecosystems could persist for a long time after their introduction and cause negative and toxic effects on the inhabitant microorganisms, and thereby affect the critical functioning they mediate (Giller et al., 2009). Therefore, understanding responses of soil microbial assemblages to copper contamination is essential to counteract its negative effect on ecosystem functions and services.

Despite a generally accepted view that the accumulation of copper might change soil microbial communities and affect microbial activities, most of the experiments were performed in short-term laboratory incubations with single soil type (Girvan et al., 2005; Lejon et al., 2008). However, the bioavailability and 
toxicity of copper might change over time due to aging and equilibration effects (Ma et al., 2006; Singh et al., 2014), so the long-term impacts of copper contamination on soil microorganisms differed across different sites. It is necessary to study whether the responses of soil microbes to long-term copper contamination are consistent under contrasting field conditions.

The goal of this study was to elucidate how the soil bacterial abundance, diversity, and community composition respond to different intensities of copper contamination under field conditions, and try to find the relationship between these changes and microbial community function. Soils were collected from two field experimental sites in China which have shown negative impacts of copper contamination on maize grain yield (Guo et al., 2010). We hypothesized that: (1) the bacterial communities could be significantly affected by long-term copper contamination in both contrasting field sites; (2) these strong effects might select copper-sensitive and-tolerant bacterial groups; (3) the shifts of bacterial communities might be observed along the copper gradients and these changes might influence the microbial functioning, such as the soil microbial biomass carbon (SMBC).

\section{MATERIALS AND METHODS}

\section{FIELD DESCRIPTION AND SOIL SAMPLING}

Soil samples were collected from two long-term experimental stations located in Dezhou $\left(37.33^{\circ} \mathrm{N}, 116.63^{\circ} \mathrm{E}\right)$, Shandong province, and Qiyang $\left(26.75^{\circ} \mathrm{N}, 111.88^{\circ} \mathrm{E}\right)$, Hunan province, China. Dezhou is characterized by a temperate continental climate with a mean annual temperature of $12.9^{\circ} \mathrm{C}$ and a mean annual rainfall of $547.5 \mathrm{~mm}$. The soil in Dezhou is classified as fluvo-aquic soil according to the Chinese soil taxonomy with a ratio of clay: silt: sand (18:18:64) and a $\mathrm{pH}$ value of 7.9 . In the Dezhou site, copper chloride powders were mixed thoroughly with surface soil and then applied back into the plots in July 2007. There were eight copper treatments, with four replicated plots for each treatment, and the copper levels were 0, 50, 100, 200, 400, 800,1600 , and $3200 \mathrm{mg} \mathrm{kg}^{-1}$ soil. The Qiyang site is characterized by a subtropical monsoon climate with a mean annual temperature of $18.1^{\circ} \mathrm{C}$ and a mean annual rainfall of $1407.5 \mathrm{~mm}$. The soil in Qiyang is classified as red soil with a ratio of clay: silt: sand (46:35:19) and a $\mathrm{pH}$ value of 4.3. The copper chloride powders were added into Qiyang soils in July 2007. The copper levels were $0,12.5,25,50,100,200,400$, and $800 \mathrm{mg} \mathrm{kg}^{-1}$ soil, with four replicated plots for each treatment.

The both sites had been planted with maize-wheat rotations under conventional agricultural management practices since 2007. Totally 128 soil samples were collected from the top $10 \mathrm{~cm}$ by mixing five soil cores for each plot in July 2011 and July 2012, respectively. Soil samples were stored at $4^{\circ} \mathrm{C}$ before analyses of physicochemical properties and $-80^{\circ} \mathrm{C}$ prior to DNA extraction.

\section{SOIL PROPERTIES ANALYSES}

Soil $\mathrm{pH}$ was measured with a soil to water ratio of 1:2.5 using a $\mathrm{pH}$ meter. Soil moisture content was determined after oven drying at $105^{\circ} \mathrm{C}$ for $8 \mathrm{~h}$. Soil organic matter (SOM) was measured by the $\mathrm{K}_{2} \mathrm{Cr}_{2} \mathrm{O}_{7}$ oxidation-reduction colorimetric method. Total nitrogen (TN) was measured by a $\mathrm{CN}$ analyzer (Vario EL III, Elementar, Germany). The copper extracted with
$0.11 \mathrm{M} \mathrm{CH}{ }_{3} \mathrm{COOH}$ was determined on ICP-OES (PerkinElmer, Waltham, MA, USA). The detailed characteristics of the soils are listed in Table 1.

\section{DETERMINATION OF SOIL MICROBIAL BIOMASS CARBON (SMBC)}

Soils were pre-incubated in semi-sealed vessels at $25^{\circ} \mathrm{C}$ for 15 days with $40 \%$ water-holding capacities (WHC). After the preincubation, three replicates of the moist soil (equivalent to $10 \mathrm{~g}$ oven-dry soil) were fumigated with ethanol-free $\mathrm{CHCl}_{3}$ for $24 \mathrm{~h}$ at $25^{\circ} \mathrm{C}$ in sealed desiccators containing water and soda-lime. The dissolved carbon of fumigated soils (E) was extracted by shaking for $30 \mathrm{~min}$ with $0.5 \mathrm{M} \mathrm{K}_{2} \mathrm{SO}_{4}$, and the dissolved carbon was also extracted from the other three replicates of non-fumigated soils $\left(\mathrm{E}_{0}\right)$. The concentrations were determined on a Liqui TOC analyzer (Liqui, Elementar, Germany). $\mathrm{SMBC}=\left(E-E_{0}\right) / \mathrm{k}(k=$ 0.45) (Wu et al., 1990).

\section{DNA EXTRACTION AND QUANTITATIVE POLYMERASE CHAIN REACTION (qPCR)}

Soil DNA was extracted using MoBio Powersoil DNA Isolation Kit (MoBio Laboratories, Carlsbad, CA, USA) according to the manufacturer's protocol. The quantity and quality of the extracted DNA were examined using a NanoDrop ${ }^{\circledR}$ ND-2000c UV-Vis spectrophotometer (NanoDrop Technologies, Wilmington, DE, USA).

Abundance of the bacterial 16S rRNA gene was determined by qPCR on an iCycler iQ 5 thermocycler (BioRad Laboratories, Hercules, CA, USA) using the primer pairs BACT1369F and PROK1492R with the probe TM1389F (Suzuki et al., 2000). Each reaction was performed in a $25 \mu \mathrm{l}$ volume containing $12.5 \mu \mathrm{l}$ Premix Ex Taq (Takara Biotechnology, Dalian, China), $0.25 \mu$ l of each primer $(10 \mu \mathrm{M}), 0.5 \mu \mathrm{l}$ of probe $(10 \mu \mathrm{M})$ and $1 \mu \mathrm{l}$ of fivefold diluted DNA template (1-10 ng). Amplification conditions were as follows: $95^{\circ} \mathrm{C}$ for $10 \mathrm{~s}, 35$ cycles of $15 \mathrm{~s}$ at $95^{\circ} \mathrm{C}$ and $1 \mathrm{~min}$ at $56^{\circ} \mathrm{C}$. Standard curves were developed using ten-fold serial dilutions of plasmid containing correct insert of the bacterial $16 \mathrm{~S}$ rRNA gene.

\section{PCR AMPLIFICATION AND SEQUENCE PROCESSING}

The V4 region of the bacterial 16S rRNA gene was amplified with the primers $515 \mathrm{f}$ and barcoded-806r which target a broad diversity of bacteria with few biases against particular groups (Bates et al., 2011). The PCR reactions in a $50 \mu \mathrm{l}$ mixture contained $20 \mu \mathrm{l}$ Premix Ex Taq (Takara Biotechnology), $0.4 \mu \mathrm{l}$ of each primer $(10 \mu \mathrm{M}), 4 \mu \mathrm{l}$ of five-fold diluted template DNA (1-10 ng) and $25.2 \mu \mathrm{l}$ sterilized water. Thermal-cycling conditions were as follows: an initial denaturation of $3 \mathrm{~min}$ at $94^{\circ} \mathrm{C}$, six touchdown cycles of $45 \mathrm{~s}$ at $94^{\circ} \mathrm{C}, 60 \mathrm{~s}$ from $65^{\circ} \mathrm{C}$ to $58^{\circ} \mathrm{C}, 70 \mathrm{~s}$ at $72^{\circ} \mathrm{C}$, followed by 22 cycles of $45 \mathrm{~s}$ at $94^{\circ} \mathrm{C}, 60 \mathrm{~s}$ at $58^{\circ} \mathrm{C}, 60 \mathrm{~s}$ at $72^{\circ} \mathrm{C}$ with a final elongation of $72^{\circ} \mathrm{C}$ for $10 \mathrm{~min}$. The PCR products were purified using a Wizard SV Gel and PCR Clean-up system (Promega, San Luis Obispo, CA, USA). The concentrations of the PCR products were fluorometrically quantified by the Qubit dsDNA HS Assay Kit (Invitrogen, Carlsbad, CA, USA) before being sequenced on the Miseq platform (Illumina, San Diego, CA, USA), at Novogene, Beijing, China.

Raw sequences were processed in QIIME 1.7.0 (Caporaso et al., 2010a). Sequences were quality trimmed and clustered 
Table 1 | Soil characteristics of the examined samples collected from Dezhou and Qiyang.

\begin{tabular}{|c|c|c|c|c|c|c|c|}
\hline Soil type & Treatment & pH & $\mathrm{H}_{2} \mathrm{O}(\%)$ & $\operatorname{SOM}\left(\mathbf{g ~ k g}^{-1}\right)$ & $\mathrm{TN}\left(\mathrm{g} \mathrm{kg}^{-1}\right)$ & $\mathrm{Cu}$ added $\left(\mathrm{mg} \mathrm{kg}^{-1}\right)$ & Extractable $\mathrm{Cu}\left(\mathrm{mg} \mathrm{kg}^{-1}\right)$ \\
\hline \multirow{5}{*}{ Fluvo-aquic soil (Dezhou) } & Cu50 & 7.7 & 14.2 & 11.3 & 0.50 & 50 & 3.6 \\
\hline & Cu200 & 8.0 & 15.8 & 11.5 & 0.44 & 200 & 38.7 \\
\hline & Cu400 & 8.0 & 15.8 & 12.8 & 0.40 & 400 & 134.6 \\
\hline & Cu800 & 7.9 & 15.5 & 12.3 & 0.44 & 800 & 406.0 \\
\hline & Cu3200 & 7.7 & 16.8 & 12.0 & 0.38 & 3200 & 1205.3 \\
\hline \multirow[t]{5}{*}{ Red soil (Qiyang) } & $\mathrm{CuO}$ & 4.3 & 20.2 & 16.2 & 0.92 & 0 & 1.4 \\
\hline & Cu12.5 & 4.3 & 20.5 & 15.6 & 0.92 & 12.5 & 5.3 \\
\hline & Cu25 & 4.3 & 20.0 & 15.9 & 0.86 & 25 & 10.5 \\
\hline & Cu50 & 4.1 & 19.3 & 15.6 & 0.88 & 50 & 22.0 \\
\hline & Cu800 & 4.4 & 12.7 & 16.5 & 0.78 & 800 & 377.9 \\
\hline
\end{tabular}

into operational taxonomic units (OTUs) at a 97\% identity threshold using uclust (Edgar, 2010). Representative sequences from individual OTUs were then aligned against the Greengenes core set (DeSantis et al., 2006) using PyNAST (Caporaso et al., 2010b). Taxonomic assignment was carried out with the RDP Classifier (Wang et al., 2007). Resampling for each sample according to the minimum sequence numbers was performed before the downstream analyses.

The principal coordinate analysis (PCoA) was used to visualize the Bray-Curtis dissimilarity matrices based on the $97 \%$ OTU level across different copper concentrations (Caporaso et al., 2010a). Diversity was characterized by calculating richness (OTU numbers, Shannon index) and evenness (Gini coefficient). The Gini coefficient (ranging from 0 to 1 ) is a value to assess the specific degree of evenness, and a higher Gini coefficient indicates lower evenness of a community (Wittebolle et al., 2009). The Gini coefficient was calculated by performing ineq package in R3.0.2 software (http://www.r-project.org/).

\section{STATISTICAL ANALYSIS}

The 16S rRNA gene copies were log-transformed prior to statistical analysis to satisfy the normality assumptions. One-Way analysis of variance (ANOVA) followed by Student-Newman-Keuls (homogeneous variance) and Welch's $t$-test (non-homogeneous variance) was conducted to compare SMBC, the bacterial abundance across different copper concentrations, and the relative abundances of different phyla between the two soils in SPSS 19.0 (IBM Co., Armonk, NY, USA). The EC50 values were calculated by logistic model using SigmaPlot 12.0 (Li et al., 2010). Distancebased multivariate linear model (DistLM) was utilized to analyze the relationships between the soil properties and the bacterial diversity as well as community compositions. Permutation multivariate analysis of variance (PerMANOVA) was used to evaluate the significance of the Bray-Curtis dissimilarity matrices across copper gradients. Boxplots plotted in R.3.0.2 were used to display the variations of the SMBC and abundance along copper gradients. Heat maps were generated to show differences in the bacterial community compositions based on the dominant phylum (with a relative abundance $>5 \%$ ) along the copper gradients. The heat map using the gplots package and PerMANOVA using the vegan package were performed in R.3.0.2. Spearman's rank test was used to assess the correlations between the abundance, Gini coefficient, OTU numbers, Shannon index, relative abundances of some groups, SMBC and copper concentrations. $P<$ 0.05 was considered to be statistically significant.

Structural equation model (SEM) was constructed to investigate the direct and indirect effects of bacterial abundance, diversity, composition, and copper concentrations on microbial biomass. Diversity was characterized by Shannon index, and composition was characterized by first axis of PCoA using Bray-Curtis dissimilarity matrix. Based on a priori and theoretical knowledge, we assumed a conceptual model that the changes of bacterial abundance, diversity, composition and copper concentrations affect the variations of microbial biomass. Maximum likelihood estimation method was used to compare the SEM with the observation. Model adequacy was determined by $\chi^{2}$-tests, goodnessof-fit index (GFI), Akaike Information Criteria (AIC), root square mean errors of approximation (RMSEA), and we revised our conceptual model according to these indexes. Adequate model fits were indicated by a non-significant $\chi^{2}$-test $(P>0.05)$, high GFI $(>0.90)$, low AIC, and low RMSEA $(<0.05)$ (Grace, 2006). SEM analysis was performed using AMOS 17.0 (Amos Development Corporation, Meadville, PA, USA).

\section{RESULTS}

VARIATIONS IN SOIL CHARACTERISTICS AND SMBC ACROSS DIFFERENT TREATMENTS

Soil $\mathrm{pH}$ varied from $7.7 \sim 8.1$ and SOM ranged from $11.3 \sim 13.4 \mathrm{~g}$ $\mathrm{kg}^{-1}$ in the fluvo-aquic soil to $4.1 \sim 4.4$ and $13.7 \sim 16.5 \mathrm{~g} \mathrm{~kg}^{-1}$, respectively, in the red soil (Table 1). Copper amendments 

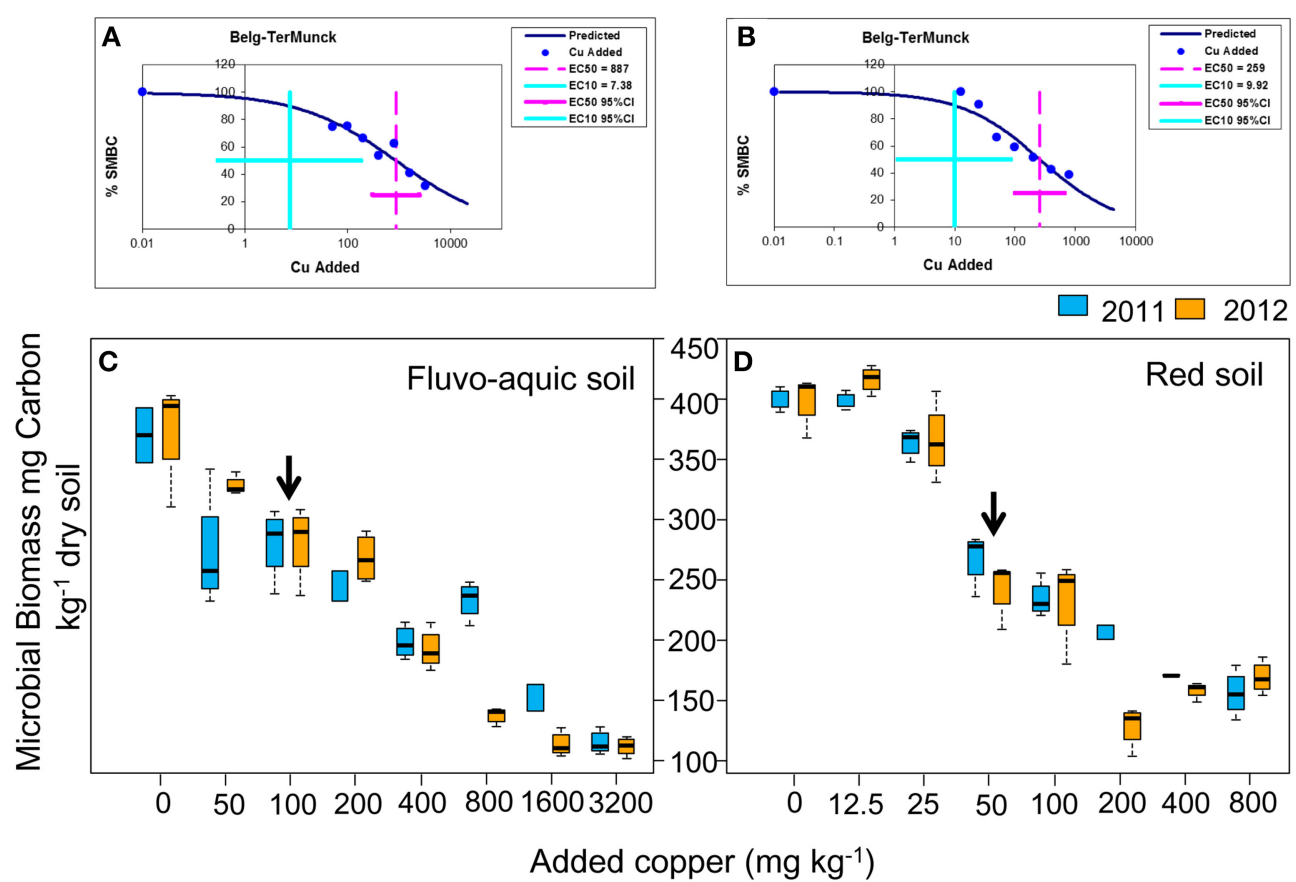

FIGURE 1 | Changes in SMBC across the eight copper concentrations in both years of the fluvo-aquic soil (C) and red soil (D), respectively. The dose-response curves between the SMBC and added copper concentrations in the fluvo-aquic soil (A) and red soil (B), respectively. The vertical pink lines indicate the EC50 values and the horizontal ones indicate $95 \%$ of the confidence intervals in $(\mathbf{A}, \mathbf{B})$. The vertical blue lines indicate the EC10 values and the horizontal ones indicate $95 \%$ of the confidence intervals in $(\mathbf{A}, \mathbf{B})$. The black arrows in (C,D) indicate the significant decreasing points of the SMBC. consistently increased the extractable copper concentrations from 0.5 to $1205.3 \mathrm{mg} \mathrm{kg}^{-1}$ in the fluvo-aquic soil and 1.4 to $377.9 \mathrm{mg}$ $\mathrm{kg}^{-1}$ in the red soil.

SMBC was highly affected by copper contamination (Figure 1). In the fluvo-aquic soil, SMBC significantly decreased from $370.2 \pm 16.1 \mathrm{mg} \mathrm{C} \mathrm{kg}^{-1}$ soil in the control treatments to $111.4 \pm 5.6$ in the Cu3200 treatments (Figure 1C). The doseeffect relationships between the SMBC and the added copper concentrations were perfectly fitted by the logistic equation in both years $(P<0.01)$, and the toxicity threshold (EC50 values) was $887 \pm 111$ added $\mathrm{Cu} \mathrm{mg} \mathrm{kg}{ }^{-1}$ soil (Figure 1A). Similar decreasing patterns were also observed in the red soil, with SMBC significantly reduced from $400.2 \pm 6.4 \mathrm{mg} \mathrm{C} \mathrm{kg}^{-1}$ soil in the $\mathrm{Cu} 0$ treatments to $170.1 \pm 10.1$ in the Cu800 treatments (Figure 1D). Further lower SMBC value was occasionally recorded in the Cu200 treatment. The significant dose-effect relationships between the SMBC and the added copper concentrations could also be observed in 2 years with the toxicity threshold (EC50 values) of $259 \pm 37$ added $\mathrm{Cu} \mathrm{mg} \mathrm{kg}{ }^{-1}$ soil (Figure 1B) $(P<0.01)$. Spearman's rank analysis found significantly negative relationships between SMBC and copper concentrations in both soils.

\section{DIFFERENTIATIONS IN THE BACTERIAL ABUNDANCE AND DIVERSITY}

In the fluvo-aquic soil, copper additions significantly decreased the bacterial 16S rRNA gene abundance from $4.93 \pm 0.64 \times 10^{10}$ copies $\mathrm{g}^{-1}$ soil in $\mathrm{Cu} 0$ to $3.36 \pm 0.58 \times 10^{9}$ copies $\mathrm{g}^{-1}$ soil in Cu3200 in 2011, but its change in 2012 was much marginal, with a significantly lower value of $2.19 \times 10^{10}$ copies $\mathrm{g}^{-1}$ soil recorded in Cu1600 (Figure 2A). In the red soil, the bacterial abundance

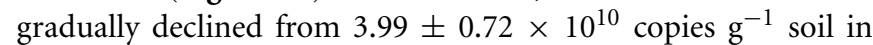
$\mathrm{Cu} 0$ to $4.11 \pm 0.82 \times 10^{9}$ in Cu800 in both years (Figure 2B). Spearman's rank analysis revealed a significantly negative correlation between the bacterial abundance with copper concentrations in both soils.

The bacterial diversity was characterized by calculating evenness (Gini coefficient) and richness (OTU numbers and Shannon index at a $97 \%$ identity threshold). Gini coefficients gradually increased along the increasing copper concentrations, with the highest values found in treatments having the highest copper amendments in both years of the both soils (Figures 3A,B). OTU numbers and Shannon index showed similar declining trends in both soils, with continuously reduced values observed along the increasing copper levels (Figures 3A,B). The sharply increasing or decreasing points were 800 and 200 added $\mathrm{Cu} \mathrm{mg} \mathrm{kg} \mathrm{mg}^{-1}$ in the fluvo-aquic soil and red soil, respectively. Significantly positive correlations between Gini coefficients and copper concentrations were found in both soils, while OTU numbers and Shannon index were significantly and negatively correlated with copper concentrations. OTU numbers and Shannon index in the fluvo-aquic soil were significantly higher than that in the red soil while the Gini coefficient displayed a reverse tendency, that is, the diversity was higher in the fluvo-aquic soil. Soil properties such as $\mathrm{pH}, \mathrm{H}_{2} \mathrm{O}$, SOM significantly determined the differences and $\mathrm{pH}$ explained $67 \%$ of the variance $(P<0.01)$. 


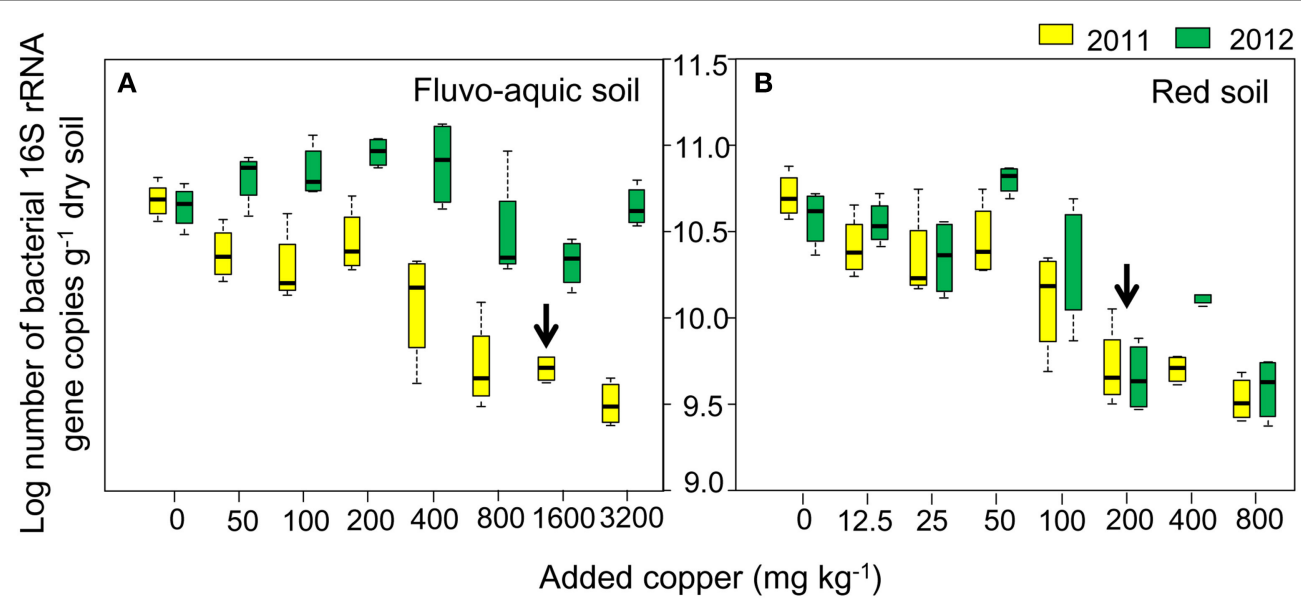

FIGURE 2 | Log-transformed abundance of the bacterial 16S rRNA gene across the eight copper concentrations in both years of the fluvo-aquic soil (A) and red soil (B), respectively. The black arrows in (A,B) indicate the significant decreasing points of the abundance.

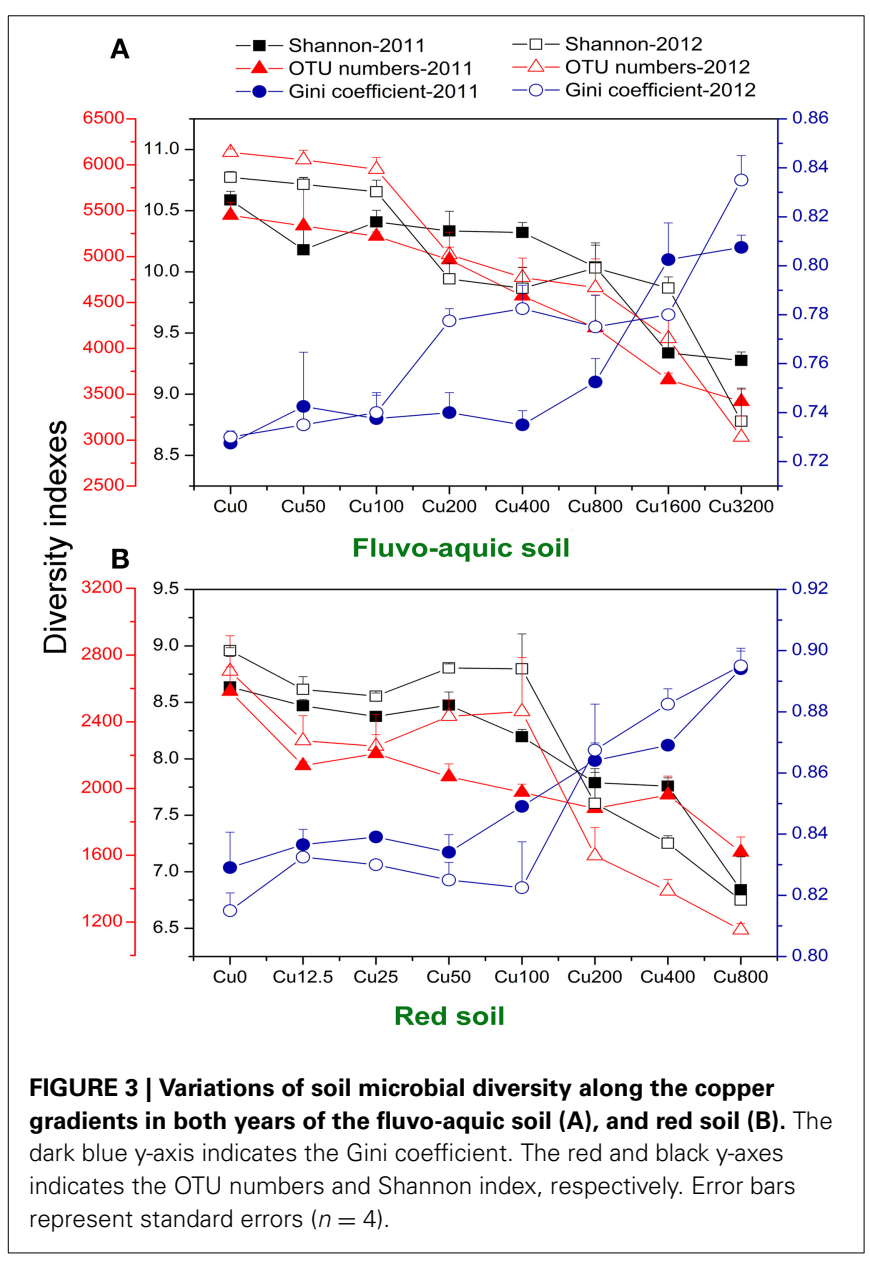

\section{COMMUNITY PROFILING OF THE BACTERIAL COMMUNITY BY ILLUMINA SEOUENCING}

Across all the 128 samples examined, the high-throughput sequencing yielded 15,472,163 high-quality bacterial $16 \mathrm{~S}$ rRNA gene sequences, and the minimum sequence number for individual sample was 47,721 . The bacterial community in the fluvo-aquic soil was highly divergent from that in the red soil (Figure 4). Proteobacteria (12.24-40.84\%), Acidobacteria (17.66-32.17\%), Chloroflexi (4.96-31.29\%), Actinobacteria (3.22-9.73\%), Planctomycetes(3.60-9.93\%), Bacteroidetes (1.79$8.76 \%)$, Gemmatimonadetes (2.43-8.52\%) and Verrucomicrobia (3.25-5.74\%) were the dominant phyla in the fluvo-aquic soil. However, the bacterial assemblages in the red soil were dominated by Actinobacteria (11.40-33.61\%),Chloroflexi (14.88-30.36\%), Proteobacteria (7.70-21.13\%), Planctomycetes (5.09-19.18\%), Acidobacteria (3.33-11.57\%), AD3 (1.47-9.20\%), WPS-2 (1.71-8.75\%), and Firmicutes (1.11-7.57\%). Compared with the fluvo-aquic soil, the relative abundances of AD3, WPS-2, Actinobacteria, Chloroflexi, Firmicutes, and Planctomycetes were significantly higher in the red soil. In contrast, the proportions of Acidobacteria, Bacteroidetes, Gemmatimonadetes, Proteobacteria, and Verrucomicrobia were significantly lower in the red soil than those in the fluvo-aquic soil (Figure 4). Soil properties such as $\mathrm{pH}, \mathrm{H}_{2} \mathrm{O}$ and SOM significantly affected bacterial community compositions, and $\mathrm{pH}$ explained $93 \%$ of the differences $(P<0.01)$.

PerMANOVA analysis showed that the bacterial communities in treatments with $\geq 800 \mathrm{mg}$ copper $\mathrm{kg}^{-1}$ soil could be obviously separated from those in treatments with lower copper concentrations in both years of the fluvo-aquic soil (Figures 5A,C). This finding was further corroborated by the partitioning effects of different copper concentration categories on the dominant bacterial phylum in the heat maps (Figures 6A,C). The differentiations of these major groups along the copper gradients were quite consistent between both years. The relative abundances of Proteobacteria, Actinobacteria, Gemmatimonadetes, and Bacteroidetes were observed to clearly increase with the increasing copper concentrations, whereas the shifts of Acidobacteria, Chloroflexi, and Planctomycetes were in reverse.

Similar to the fluvo-aquic soil, the bacterial communities in both years of the red soil were partitioned into two clusters: one 


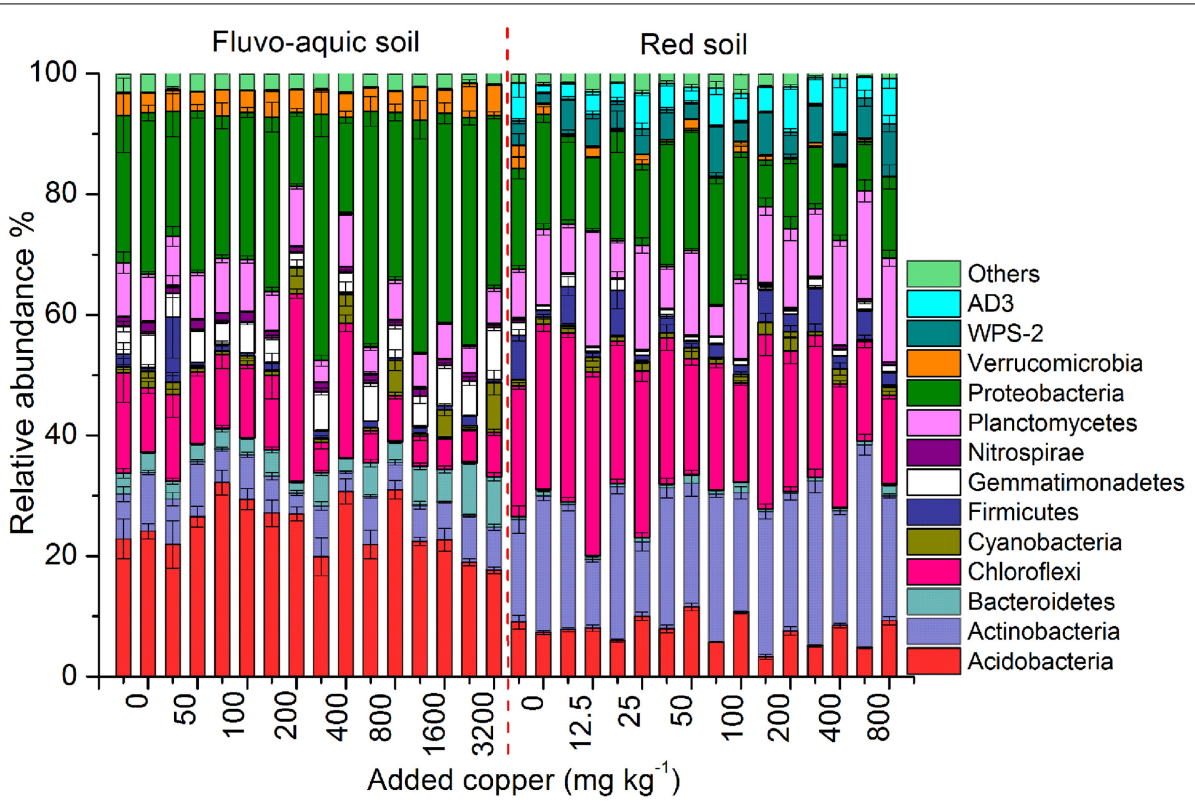

FIGURE 4 | Changes in the bacterial community compositions across the different copper concentrations in both years of the fluvo-aquic soil and red soil. Error bars represent standard errors $(n=4)$. Here the two bars for each concentration represent the relative abundance of different groups in 2011 and 2012, respectively.

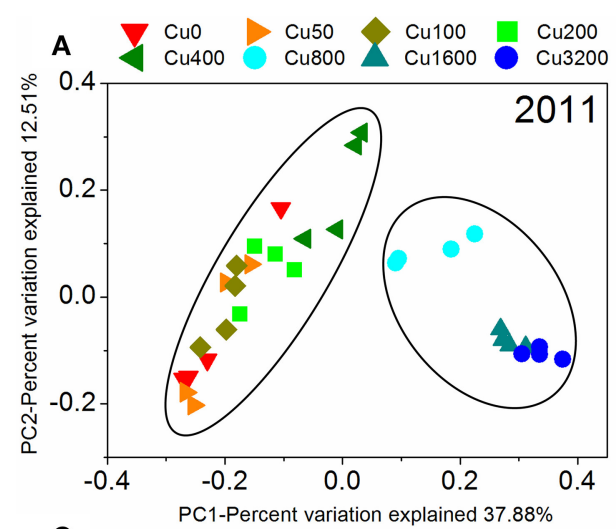

C

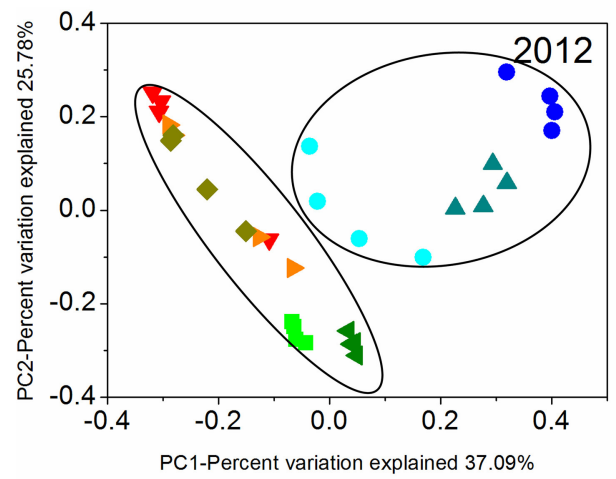

Fluvo-aquic soil

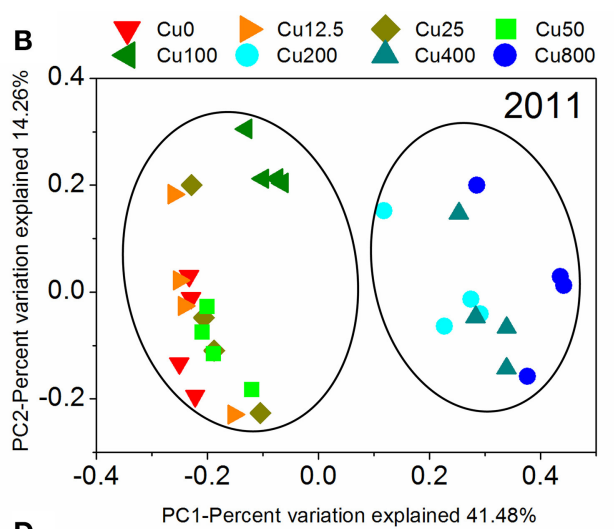

D

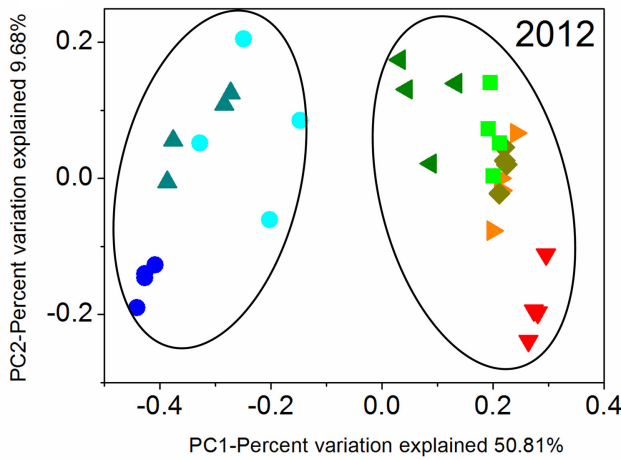

Red soil

FIGURE 5 | The principal coordinate analysis (PCoA) derived from the Bray-Curtis dissimilarity matrices based on the $97 \%$ OTU level of the bacterial community compositions across different copper treatments in the fluvo-aquic soil ( $A$ and $C$ ) and red soil (B and $D$ ) at 2 sampling years. 


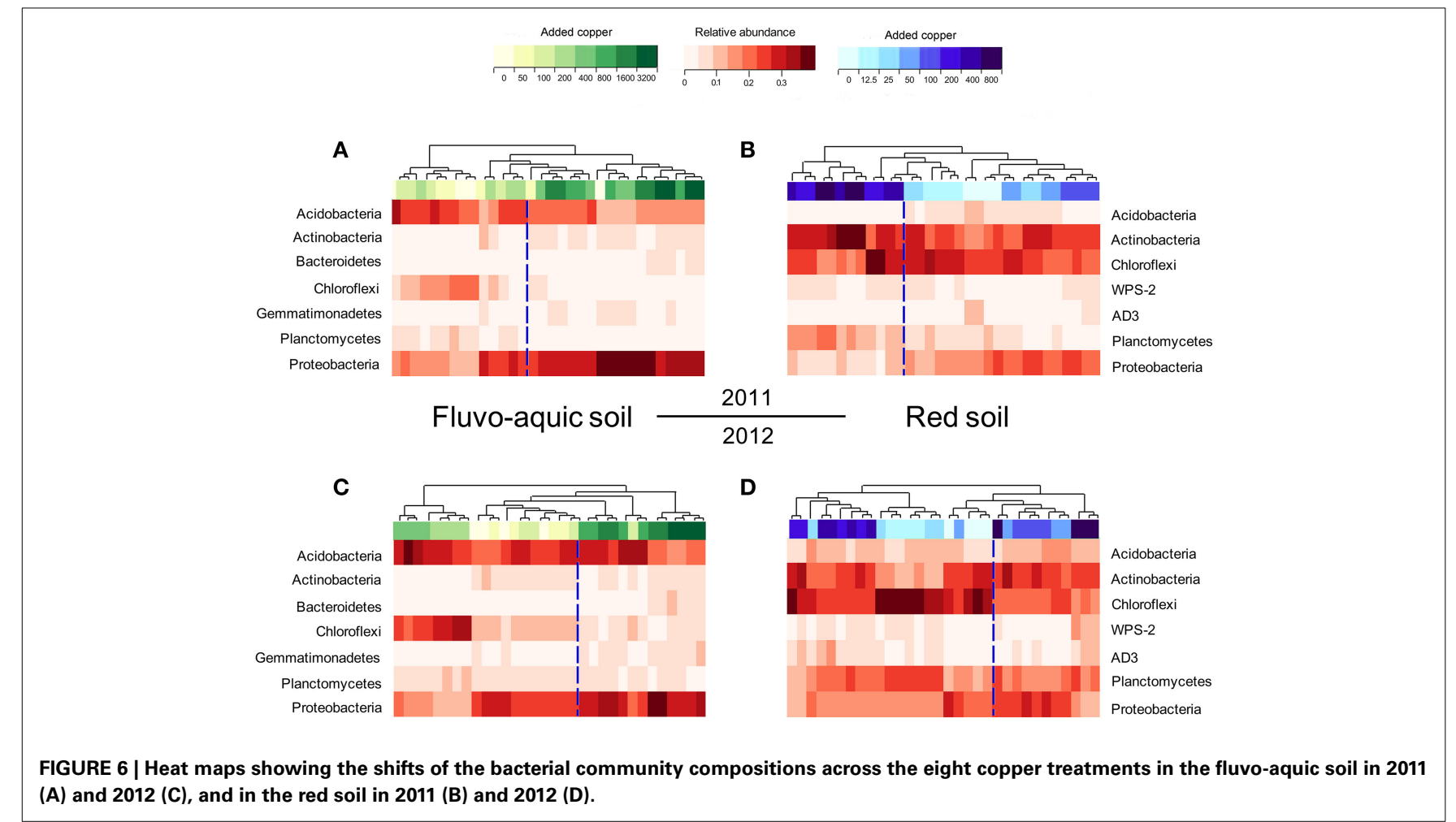

from treatments with $\geq 200 \mathrm{mg}$ copper $\mathrm{kg}^{-1}$ soil, and another from treatments with $<200 \mathrm{mg}$ copper $\mathrm{kg}^{-1}$ soil (PerMANOVA analysis, Figures 5B,D; Supplementary Figure 1). The significant impacts of copper contamination on the bacterial community compositions were further supported by clustering of the dominant bacterial phylum corresponding to different copper levels in the heat maps (Figures 6B,D). Similar patterns in shifts of these major bacterial groups along the copper gradients were observed in 2011 and 2012. Generally, Actinobacteria, WPS-2, and Planctomycetes tended to have higher relative abundances at higher copper levels, Proteobacteria were more abundant at medium copper levels, while Chloroflexi showed higher frequencies at lower copper levels and reached the lowest at Cu800 in both years. Acidobacteria and AD3 tended to be higher at lower copper levels in 2011, but had wider span across different copper levels in 2012.

\section{RELATIONSHIPS BETWEEN THE BACTERIAL ABUNDANCE, DIVERSITY, COMMUNITY COMPOSITION WITH SMBC}

Spearman's rank analyses found a significantly positive correlation between the bacterial abundance and SMBC under the copper contamination in both soils. Intriguingly, Gini coefficients had significantly negative correlations with SMBC, while OTU numbers and Shannon index had positive relationships with SMBC in both copper-contaminated soils. Moreover, the relative abundance of Chloroflexi was significantly and positively correlated with SMBC in both copper-contaminated soils (Supplementary Table 1).

The final SEM explained 74 and $73 \%$ of the variation in microbial biomass in the two soils, respectively (Figures 7A,B).
Bacterial community composition and diversity showed directly negative effects on the microbial biomass in the fluvo-aquic soil $(\lambda=-0.59, P<0.001 ; \lambda=-0.28, P<0.05$, Figure 7A), and the similar negative effects were observed in the red soil $(\lambda=-1.27, P<0.001 ; \lambda=-0.46, P<0.05$, Figure 7B). Compared with these direct effects, copper concentrations indirectly affected the microbial biomass by influencing bacterial community composition and diversity $(\lambda=-0.765$, Figure 7C; $\lambda=-0.700$, Figure 7D). The total effects of bacterial community composition and diversity on the microbial biomass were also displayed in Figures 7C,D.

\section{DISCUSSION}

SIMILAR RESPONSES OF THE BACTERIAL COMMUNITIES IN TWO CONTRASTING SOILS TO THE COPPER CONTAMINATION

Although the long-term effects of copper contamination on microbial communities have been investigated in some studies (Macdonald et al., 2008; Singh et al., 2014), the responses of microbial community composition and function to copper contaminations differed across various sites and no firm conclusions had been drawn. Soil type is regarded as a key determinant of microbial communities (Drenovsky et al., 2010), and differences in soil basic characteristics can induce different microbial assemblages. As evidenced in this study, significant differences in bacterial communities including diversity and compositions between the two soils might be ascribed to the differences in soil properties especially $\mathrm{pH}$. Our results showed that the relative abundances of Gemmatimonadetes, Proteobacteria, Bacteroidetes, and Verrucomicrobia were higher in the neutral/alkaline fluvoaquic soil, which were in agreement with previous studies that 
A

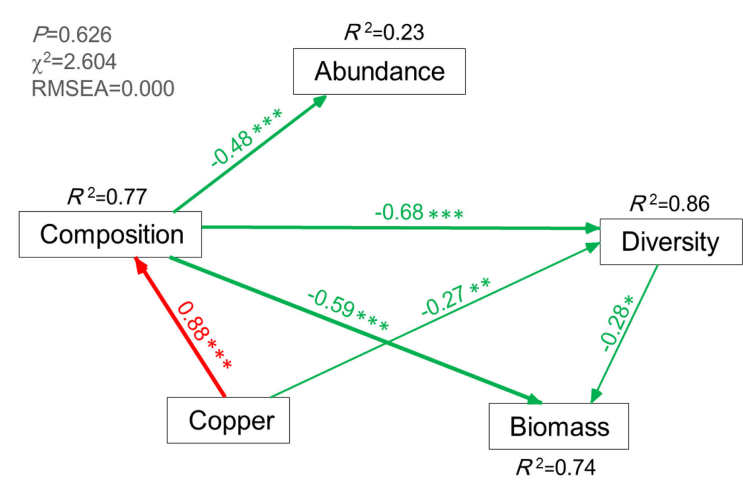

C

\begin{tabular}{cccc}
\hline \multicolumn{3}{c}{ Standardized total effects } \\
\hline & Copper & Composition & Diversity \\
\cline { 2 - 4 } Composition & 0.88 & 0 & 0 \\
Shannon & -0.867 & -0.68 & 0 \\
Abundance & -0.424 & -0.482 & 0 \\
Biomass & -0.765 & -0.784 & -0.282
\end{tabular}

Fluvo-aquic soil

FIGURE 7 | Structural Equation Model (SEM) showing the causal relationships among bacterial abundance, diversity, biomass, community composition, and copper concentrations in the

fluvo-aquic soil (A) and red soil (B). The final model fits the data well (A): maximum likelihood, $x^{2}=2.604, d f=4, P=0.626$; goodness-of-fit index $(\mathrm{GFI})=0.984$; Akaike Information Criteria $(\mathrm{AIC})=24.60$; root square mean errors of approximation (RMSEA) $=0.000$. (B): maximum

\section{B}

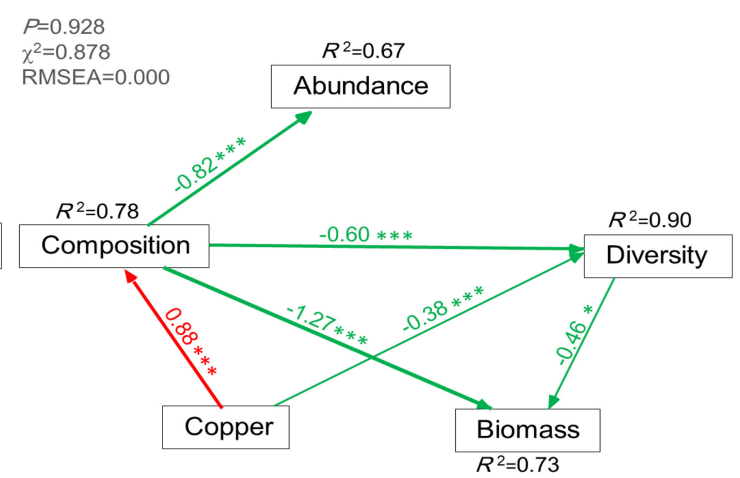

D

\begin{tabular}{cccc}
\hline \multicolumn{3}{c}{ Standardized total effects } \\
\hline & Copper & Composition & Diversity \\
\cline { 2 - 4 } Composition & 0.884 & 0 & 0 \\
Shannon & -0.908 & -0.6 & 0 \\
Abundance & -0.725 & -0.82 & 0 \\
Biomass & -0.700 & -0.991 & -0.465
\end{tabular}

Red soil

likelihood, $\chi^{2}=0.878, d f=4, P=0.928$; goodness-of-fit index (GFI) = 0.994; Akaike Information Criteria $(A I C)=22.88$; root square mean errors of approximation (RMSEA) $=0.000$. Red and green lines indicate positive and negative pathways, respectively. Width of the line indicates the strength of the relationships. Standardized total effects (direct and indirect effects) were derived from the structural equation modeling (C,D). ${ }^{*} P<0.05,{ }^{* *} P<0.01$, ${ }^{* * *} P<0.001$. these groups were favored under high $\mathrm{pH}(7 \sim 8)$ conditions ( $\mathrm{He}$ et al., 2012; Fierer et al., 2013; Marcina et al., 2013). Interestingly, we also found that the relative abundance of Acidobacteria was higher in the fluvo-aquic soil than that in the red soil. According to the study of Jones et al. (2009), the distribution pattern of Acidobacteria was mainly regulated by soil $\mathrm{pH}$, and different subgroups might respond differently to soil $\mathrm{pH}$. In our study, the major subgroup of Acidobacteria in the fluvo-aquic soil belonged to subgroup 6 , and this subgroup was reported to be prevailing in the high $\mathrm{pH}$ and low SOM environment (Zimmermann et al., 2005; Jones et al., 2009) which was similar to the characteristics of the examined fluvo-aquic soil. The diversity of soil bacteria is also dependent on soil pH (Hu et al., 2013; Marcina et al., 2013). In our study the bacterial diversity in the red soil was lower than that in the fluvo-aquic soil, which was corroborated by the finding that the bacterial diversity of acidic soil $(\mathrm{pH} 4 \sim 5)$ was much lower compared with the neutral soils ( $\mathrm{pH} 7 \sim 8$ ) (Fierer and Jackson, 2006). Based on the data from these long-term experimental sites, the soil $\mathrm{pH}$ values varied slightly between 2007 and $2011 / 2012$, indicating that added copper did not significantly affect the soil $\mathrm{pH}$.

The obvious differences of the thresholds between two soils were also found in our study, indicating the different EC50 values characterized by the SMBC and the thresholds that bacterial community compositions significantly separated across different copper concentrations in two soils. The toxicity thresholds characterized by SMBC obtained from the fluvo-aquic soil were significantly higher than those from the red soil, in addition, significant changes of the bacterial community compositions were induced by 800 added $\mathrm{Cu} \mathrm{mg} \mathrm{kg}{ }^{-1}$ soil in the fluvo-aquic soil, and $200 \mathrm{mg} \mathrm{kg}^{-1}$ soil in the red soil (Figure 5). The probable reason could be ascribed to the higher $\mathrm{pH}$ in the alkaline fluvo-aquic soil, indicating that much of the $\mathrm{Cu}^{2+}$ could be precipitated as $\mathrm{Cu}_{2}(\mathrm{OH})_{2} \mathrm{CO}_{3}$ (malachite) and $\mathrm{Cu}(\mathrm{OH})_{2}$ (Ma et al., 2006).

Although the two agricultural soils encompassed contrasting bacterial communities, the bacterial community compositions displayed consistent changes in response to the increasing copper gradients in both soils (Figure 5). Macdonald et al. (2011) found a similar response of bacterial, archaeal, and fungal community structures to copper and zinc contaminations in arable and grassland soils. However, apart from the community compositions, whether the soil microbial abundance, diversity and function all together respond similarly to the copper contamination across various sites remains unknown. Although the site effect was assumed to be the strongest determinant (Macdonald et al., 2011), our results did show a consistent shift in microbial community 
structure, and a consistent reduction of bacterial abundance, diversity and function, represented by SMBC, along the increasing copper gradients in both years of both soils. Therefore, our study provides strong evidence that the effects of copper contamination on bacterial communities are consistent across time and space (Singh et al., 2014).

\section{CRITICAL COPPER-SENSITIVE AND -TOLERANT BACTERIAL GROUPS IDENTIFIED IN THE LONG-TERM FIELD STUDIES}

One objective of our work was to identify key bacterial groups that might be responsive to copper contamination. It is likely that different microbial groups inhabit different niches within an ecosystem, and therefore differ in their sensitivity to copper contamination (Giller et al., 1998). Progressive shifts of the bacterial community compositions induced by the copper gradients were observed in our study, implying the dose-related effects as previously suggested (Brandt et al., 2010; Macdonald et al., 2011). The shifts might be explained by that some tolerant phylotypes were selected while sensitive ones were obviously reduced (Singh et al., 2014), and the adaption mechanism of these groups was attributed to different activities for biosorption, bioprecipitation, extracellular sequestration and chelation (Haferburg and Kothe, 2007). Specifically, we found that Actinobacteria was a copper tolerant group whereas Acidobacteria and Chloroflexi were copper sensitive groups in both soils.

A higher copper sensitivity of Acidobacteria has been reported in previous studies (Wakelin et al., 2010; Macdonald et al., 2011). Acidobacteria could thrive in soils with totally different physical and chemical characteristics and contribute to the terrestrial carbon cycle especially carbon storage (Trivedi et al., 2013), hence their apparent sensitivity to copper may be helpful to evaluate the impacts of copper on below-ground microorganisms and the relevant functioning. Chloroflexi, as a dominant group in both soils in our study, involved in carbon (Hug et al., 2013) cycling in the subsurface and exhibited copper sensitivity, which might be recognized as a new copper indicator. The tolerance of Actinobacteria to copper contamination has been reported in numerous studies (Haferburg and Kothe, 2007; Sun et al., 2010), and the resistance mechanisms could be explained by the active metal efflux transport systems or by complexation with metal chelating substances for limiting free ions of metals within the cell (Haferburg and Kothe, 2007). As for a microbial community, species with high resistance to the heavy metal contamination might compensate the loss of other species affected by the contamination, which guaranteed the stable community (Awasthi et al., 2014).

\section{SIGNIFICANT INFLUENCES OF THE COPPER CONTAMINATION ON SOIL BACTERIAL COMMUNITIES AND THEIR POTENTIAL EFFECTS ON MICROBIAL FUNCTIONING}

The significant loss of microbial diversity induced by copper has been reported in the studies of contaminated soil (Singh et al., 2014). More and more studies reported that microbial assemblages respond sensitively to copper contamination via changes in community composition and/or function (Macdonald et al., 2011; Griffiths and Philippot, 2012; Li et al., 2014a). As evidenced in this study, despite the different soil types, we found that bacterial diversity significantly decreased along the copper gradients in both agricultural soils, and the apparent shifts of bacterial community compositions were also observed. The microbial biomass accumulation provides important information about community functioning and could be regarded as a functional indicator (Shade et al., 2012; Awasthi et al., 2014). In our study, the microbial biomass, as presented by SMBC, also decreased with the increasing copper concentrations. However, the bacterial abundance did not show a significantly decreasing tendency as the SMBC. The most probable reason might be explained by the variations of fungi communities which also contribute to the productivity of the SMBC.

The role of biodiversity acting as ecological insurance is crucial for maintaining the ecosystem functioning under environmental fluctuations (Loreau and de Mazancourt, 2013). As for the bacterial diversity in this study, the richness and evenness were positively correlated with SMBC in both copper contaminated soils, and this finding was in agreement with a strongly positive linear relationship between soil biodiversity and ecosystem multifunctionality (Wagg et al., 2014). The changes in soil microbial community compositions also influenced ecosystem processes related to nutrient cycling (Wagg et al., 2014), and our findings that the relative abundance of Chloroflexi was positively correlated with SMBC supported this hypothesis. Chloroflexi are also considered to be involved in carbon cycling such as $\mathrm{CO}_{2}$ fixation in the subsurface (Hug et al., 2013), which contribute to the production of microbial biomass carbon. Moreover, the thresholds that bacterial diversity and community composition obviously changed were 800 and 200 added $\mathrm{mg} \mathrm{kg}^{-1}$ copper in the fluvoaquic soil and red soil, respectively, which were similar to the toxicity thresholds (EC50 values) by fitting the dose-effect relationships between SMBC and added copper concentrations. SEM analysis further established the relationships between the bacterial communities and the microbial biomass, which demonstrated that the shifts in bacterial community compositions and diversity could have largely determined the variations of microbial biomass in both soils. This finding further supported that the changes in microbial communities could indeed influence the microbes-mediated function.

Overall, these results provide remarkable evidence that both the shifts of diversity and composition of bacterial assembly might result in the changes of SMBC under the copper contamination, and they agree with that highly diverse communities are prone to maintaining higher community productivity (Awasthi et al., 2014). Biodiversity loss negatively affecting the ecosystem services has already been recognized in the aboveground communities (Zavaleta et al., 2010), recent research gradually extends to the below-ground environment, suggesting that loss of soil biodiversity and changes in soil community composition impact the performance of overall ecosystem and threaten ecosystem multifunctionality and sustainability (Wagg et al., 2014). Our consistent findings in contrasting soil types support this conclusion, and this study might also contribute to the work focusing on the effects of diversity and compositions of soil microbial communities on ecosystem functions enduring the heavy metal contamination. However, there was an obvious limitation in our study that we only measured the microbial biomass and did not investigate multiple microbial 
functions, therefore, more comprehensive work is desirable in the future.

In conclusion, by tracking the detailed feedback responses of soil bacteria to copper contamination in two different soil types, we provide critical field-based evidence that copper contamination over the long-term could lead to remarkable changes in the bacterial abundance and compositions, and significant losses of diversity. These taxonomic changes might result in alternations of major functional capacities, as represented by the consistent reduction in the microbial biomass production under the copper contamination. The copper tolerant guilds identified in this study could serve as a basis for future discovery of microbial assemblages with bioremediation potential and strong adaptability to be utilized in copper contaminated sites. Our findings caution the negative impacts on terrestrial ecosystem security brought about by intensive human activities, and highlight the necessity of preserving belowground biodiversity for sustainable ecosystem functioning.

\section{ACKNOWLEDGMENTS}

This work was financially supported by the Strategic Priority Research Program of the Chinese Academy of Sciences (XDB15020200) and the National Science Foundation of China (41025004, 51221892). We gratefully acknowledge Li-Mei Zhang and Miao-Miao Zhang for their assistance during the field sampling.

\section{SUPPLEMENTARY MATERIAL}

The Supplementary Material for this article can be found online at: http://www.frontiersin.org/journal/10.3389/fmicb. 2015.00031/abstract

\section{REFERENCES}

Awasthi, A., Singh, M., Soni, S. K., Singh, R., and Kalra, A. (2014). Biodiversity acts as insurance of productivity of bacterial communities under abiotic perturbations. ISME. J. 8, 2445-2452. doi: 10.1038/ismej.2014.91

Bates, S. T., Berg-Lyons, D.,Caporaso, J. G., Walters, W. A., Knight, R., and Fierer, N. (2011). Examining the global distribution of dominant archaeal populations in soil. ISME. J. 5, 908-917. doi: 10.1038/ismej.2010.171

Bissett, A., Brown, M. V., Siciliano, S. D., and Thrall, P. H. (2013). Microbial community responses to anthropogenically induced environmental change: towards a systems approach. Ecol. Lett. 16, 128-139. doi: 10.1111/ele.12109

Brandt, K. K., Frandsen, R. J. N., Holm, P. E., and Nybroe, O. (2010). Development of pollution-induced community tolerance is linked to structural and functional resilience of a soil bacterial community following a five-year field exposure to copper. Soil Biol. Biochem. 42, 748-757. doi: 10.1016/j.soilbio.2010.01.008

Caporaso, J. G., Bittinger, K., Bushman, F. D., De Santis, T. Z., Andersen, G. L., and Knight, R. (2010b). PyNAST: a flexible tool for aligning sequences to a template alignment. Bioinformatics 26, 266-267. doi: 10.1093/bioinformatics/btp636

Caporaso, J. G., Kuczynski, J., Stombaugh, J., Bittinger, K., Bushman, F. D., Costello, E. K., et al. (2010a). QIIME allows analysis of high-throughput community sequencing data. Nat. Methods 7, 335-336. doi: 10.1038/nmeth.f.303

DeSantis, T. Z., Hugenholtz, P., Larsen, N., Rojas, M., Brodie, E. L., Keller, K., et al. (2006). Greengenes, a chimera-checked 16S rRNA gene database and workbench compatible with ARB. Appl. Environ. Microbiol. 72, 5069-5072. doi: 10.1128/AEM.03006-05

Drenovsky, R. E., Steenwerth, K. L., Jackson, L. E., and Scow, K. M. (2010). Land use and climatic factors structure regional patterns in soil microbial communities. Glob. Ecol. Biogeogr. 19, 27-39. doi: 10.1111/j.1466-8238.2009.00486.x

Edgar, R. C. (2010). Search and clustering orders of magnitude faster than BLAST. Bioinformatics 26, 2460-2461. doi: 10.1093/bioinformatics/btq461
Fierer, N., and Jackson, R. B. (2006). The diversity and biogeography of soil bacterial communities. Proc. Natl. Acad. Sci. U.S.A. 103, 626-631. doi: 10.1073/pnas.0507535103

Fierer, N., Ladau, J., Clemente, J. C., Leff, J. W., Owens, S. M., Pollard, K. S., et al. (2013). Reconstructing the microbial diversity and function of preagricultural tallgrass prairie soils in the united states. Science 342, 621-624. doi: 10.1126/science. 1243768

Giller, K. E., Witter, E., and McGrath, S. P. (1998). Toxicity of heavy metals to microorganisms and microbial processes in agricultural soils: a review. Soil Biol. Biochem. 30, 1389-1414. doi: 10.1016/S0038-0717(97)00270-8

Giller, K. E., Witter, E., and McGrath, S. P. (2009). Heavy metals and soil microbes. Soil Biol. Biochem. 41, 2031-2037. doi: 10.1016/j.soilbio.2009.04.026

Girvan, M. S., Campbell, C. D., Killham, K., Prosser, J. I., and Glover, L. A. (2005). Bacterial diversity promotes community stability and functional resilience after perturbation. Environ. Microbiol. 7, 301-313. doi: 10.1111/j.14622920.2005.00695.x

Grace, J. B. (2006). Structural Equation Modeling and Natural Systems. Cambridge; New York: Cambridge University Press.

Griffiths, B. S., and Philippot, L. (2012). Insights into the resistance and resilience of the soil microbial community. FEMS. Microbiol. Rev. 37, 112-129. doi: 10.1111/j.1574-6976

Guo, X. Y., Zuo, Y. B., Wang, B. R., Li, J. M., and Ma, Y. B. (2010). Toxicity and accumulation of copper and nickel in maize plants cropped on calcareous and acidic field soils. Plant Soil. 333, 365-373. doi: 10.1007/s11104-010-0351-0

Haferburg, G., and Kothe, E. (2007). Microbes and metals: interactions in the environment. J. Basic Microbiol. 47, 453-467. doi: 10.1002/jobm.200700275

He, J. Z., Hu, H. W., and Zhang, L. M. (2012). Current insights into the autotrophic thaumarchaeal ammonia oxidation in acidic soils. Soil Biol. Biochem. 55, 146-154. doi: 10.1016/j.soilbio.2012.06.006

Hu, H. W., Zhang, L. M., Dai, Y., Di, H. J., and He, J. Z. (2013). pH-dependent distribution of soil ammonia oxidizers across a large geographical scale as revealed by high-throughput pyrosequencing. J. Soils Sediments 13, 1439-1449. doi: 10.1007/s11368-013-0726-y

Hug, L. A.,Castelle, C. J.,Wrighton, K. C., Thomas, B. C., Sharon, I., Frischkorn, K. R., et al. (2013). Community genomic analyses constrain the distribution of metabolic traits across the Chloroflexi phylum and indicate roles in sediment carbon cycling. Microbiome 1, 1-17. doi: 10.1186/2049-2618-1-22

Jones, R. T., Robeson, M. S., Lauber, C. L., Hamady, M., Knight, R., and Fierer, N. (2009). A comprehensive survey of soil acidobacterial diversity using pyrosequencing and clone library analyses. ISME J. 3, 442-453. doi: 10.1038/ismej.2008.127

Lejon, D. P. H., Martins, J. M. F., Leveque, J., Spadini, L., Pascault, N., Landry, D., et al. (2008). Copper dynamics and impact on microbial communities in soils of variable organic status. Environ. Sci. Technol. 42, 2819-2825. doi: 10.1021/es071652r

Li, B., Ma, Y. B., Mclaughlin, M. J., Kirby, J. K., Cozens, G., and Liu, J. F. (2010). Influences of soil properties and leaching on copper toxicity to barley root elongation. Environ. Toxicol. Chem. 29, 835-842. doi: 10.1002/etc.108

Li, J., Zheng, Y. M., Liu, Y. R., Ma, Y. B., Hu, H. W., and He, J. Z. (2014a). Initial copper stress strengthens the resistance of soil microorganisms to a subsequent copper stress. Microb. Ecol. 67, 931-941. doi: 10.1007/s00248-014-0391-8

Li, Z. Y., Ma, Z. W., van der Kuijpa, T. J., Yuan, Z. W., and Huang, L. (2014b). A review of soil heavy metal pollution from mines in China: pollution and health risk assessment. Sci. Total Environ. 468-469, 843-853. doi: 10.1016/j.scitotenv.2013.08.090

Loreau, M., and de Mazancourt, C. (2013). Biodiversity and ecosystem stability: a synthesis of underlying mechanisms. Ecol. Lett. 16, 106-115. doi: 10.1111/ele.12073

Ma, Y. B., Lombi, E., Oliver, I. W., Nolan, A. L., and Mclaughlin, M. J. (2006). Longterm aging of copper added to soils. Environ. Sci. Technol. 40, 6310-6317. doi: 10.1021/es060306r

Macdonald, C. A., Campbell, C. D., Bacon, J. R., and Singh, B. K. (2008). Multiple profiling of soil microbial communities identifies potential genetic markers of metal-enriched sewage sludge. FEMS Microbiol. Ecol. 65, 555-564. doi: 10.1111/j.1574-6941.2008.00538.x

Macdonald, C. A., Clark, I. M., Zhao, F. J., Hirsch, P. R., Singh, B. K., and McGrath, S. P. (2011). Long-term impacts of zinc and copper enriched sewage sludge additions on bacterial, archaeal and fungal communities in arable and grassland soils. Soil Biol. Biochem. 43, 932-941. doi: 10.1016/j.soilbio.2011.01.004 
Marcina, C., Marcin, G., Justynac, M., Katarzynac, K., and Mariac, N. (2013). Diversity of microorganisms from forest soils differently polluted with heavy metals. Appl Soil Ecol. 64, 7-14. doi: 10.1016/j.apsoil.2012.11.004

Pietrzak, U., and McPhail, D. C. (2004). Copper accumulation, distribution and fractionation in vineyard soils of Victoria, Australia. Geoderma 122, 151-166. doi: 10.1016/j.geoderma.2004.01.005

Shade, A., Peter, H., Allison, S. D., Baho, D., Berga, M., Buergmann, H., et al. (2012). Fundamentals of microbial community resistance and resilience. Front. Microbiol. 3: 417. doi: 10.3389/fmicb.2012.00417

Singh, B. K., Quince, C., Macdonald, C. A., Khachane, A., Thomas, N., Al-Soud, W. A., et al. (2014). Loss of microbial diversity in soils is coincident with reductions in some specialized functions. Environ. Microbiol. 16, 2408-2420. doi: 10.1111/1462-2920.12353

Smith, S. R. (2009). A critical review of the bioavailability and impacts of heavy metals in municipal solid waste composts compared to sewage sludge. Environ. Int. 35, 142-156. doi: 10.1016/j.envint.2008.06.009

Sun, L. N., Zhang, Y. F., He, L. Y., Chen, Z. J., Wang, Q. Y., Qian, M., et al. (2010). Genetic diversity and characterization of heavy metal-resistant-endophytic bacteria from two copper-tolerant plant species on copper mine wasteland. Bioresour. Technol. 101, 501-509. doi: 10.1016/j.biortech

Suzuki, M. T., Taylor, L. T., and DeLong, E. F. (2000). Quantitative analysis of small-subunit rRNA genes in mixed microbial populations via $5^{\prime}$-nuclease assays. Appl. Environ. Microbiol. 66, 4605-4614. doi: 10.1128/AEM.66.11.46054614.2000

Trivedi, P., Anderson, I. C., and Singh, B. K. (2013). Microbial modulators of soil carbon storage: integrating genomic and metabolic knowledge for global prediction. Trends Microbiol. 21, 614-651. doi: 10.1016/j.tim.2013. 09.005

Wagg, C., Bender, S. F., Widmer, F., and van der Heijden, M. G. A. (2014). Soil biodiversity and soil community composition determine ecosystem multifunctionality. Proc. Natl. Acad. Sci. U.S.A. 111, 5266-5270. doi: 10.1073/pnas.1320054111

Wakelin, S. A., Chu, G. X., Lardner, R., Liang, Y. C., and McLaughlin, M. J. (2010). A single application of $\mathrm{Cu}$ to field soil has long term effects on bacterial community structure, diversity, and soil processes. Pedobiologia 53, 149-158. doi: 10.1016/j.pedobi.2009.09.002

Wang, Q., Garrity, G. M., Tiedje, J. M., and Cole, J. R. (2007). Naive Bayesian classifier for rapid assignment of rRNA sequences into the new bacterial taxonomy. Appl. Environ. Microbiol. 73, 5261-5267. doi: 10.1128/AEM.00062-07
Wittebolle, L., Marzorati, M., Clement, L., Balloi, A., Daffonchio, D., Heylen, K., et al. (2009). Initial community evenness favours functionality under selective stress. Nature. 458, 623-626. doi: 10.1038/nature07840

Wu, J. S., Joergensen, R. G., and Pommerening, B. (1990). Measurement of soil microbial biomass $\mathrm{C}$ by fumigation-extraction-an automated procedure. Soil Biol. Biochem. 22, 1167-1169. doi: 10.1016/0038-0717(90)90046-3

Zavaleta, E. S., Pasari, J. R., Hulvey, K. B., and Tilman, G. D. (2010). Sustaining multiple ecosystem functions in grassland communities requires higher biodiversity. Proc. Natl. Acad. Sci. U.S.A. 107, 1443-1446. doi: 10.1073/pnas.0906829107

Zhou, Z. Y., Fan, Y. P., and Wang, M. J. (2000). Heavy metals contamination in vegetables and their control in China. Food Rev. Int. 16, 239-255. doi: 10.1081/FRI-100100288

Zhuang, P., McBride, M. B., Xia, H. P., Li, N. Y., and Li, Z. (2009). A. Health risk from heavy metals via consumption of food crops in the vicinity of Dabaoshan mine, South China. Sci. Total Environ. 407, 1551-1561. doi: 10.1016/j.scitotenv.2008.10.061

Zimmermann, J., Gonzalez, J. M., Saiz-Jimenez, C., and Ludwig, W. (2005). Detection and phylogenetic relationships of highly diverse uncultured acidobacterial communities in altamira cave using 23S rRNA sequence analyses. Geomicrobiol. J. 22, 379-388. doi: 10.1080/01490450500248986

Conflict of Interest Statement: The authors declare that the research was conducted in the absence of any commercial or financial relationships that could be construed as a potential conflict of interest.

Received: 28 November 2014; accepted: 11 January 2015; published online: 02 February 2015.

Citation: Li J, Ma Y-B, Hu H-W, Wang J-T, Liu Y-R and He J-Z (2015) Field-based evidence for consistent responses of bacterial communities to copper contamination in two contrasting agricultural soils. Front. Microbiol. 6:31. doi: 10.3389/fmicb. 2015.00031

This article was submitted to Terrestrial Microbiology, a section of the journal Frontiers in Microbiology.

Copyright (c) $2015 \mathrm{Li}, \mathrm{Ma}, \mathrm{Hu}$, Wang, Liu and He. This is an open-access article distributed under the terms of the Creative Commons Attribution License (CC BY). The use, distribution or reproduction in other forums is permitted, provided the original author(s) or licensor are credited and that the original publication in this journal is cited, in accordance with accepted academic practice. No use, distribution or reproduction is permitted which does not comply with these terms. 